\title{
Review of: "Dairy vs. beef production - expert views on welfare"
}

\author{
Amelia Garcia-Ara ${ }^{1}$ \\ 1 University of Nottingham
}

Potential competing interests: The author(s) declared that no potential competing interests exist.

Thanks for sharing this with me. Great to see research in this area, definitely interested in all that can help animal welfare and its alignment in between consumers demands/perceptions/agricultural practices, and improvements that farmers can implement and gain benefit from too. Although the experts seem to me very well chosen and their opinons are really interesting, something in the intro on the lines that this paper will review the expert opinion on a typical intensive dairy production ( and explain what this is, for example high yielding >300 cattle/herd using bock or year around calving) and typical intensive beef production (same thing) would help to set the baseline as rose veal and white meat producton for example are all thrown into one category. Did you have a look at countries differences or at least Europe/NorthAmerican/South American/Others? This would really be very interesting as it feels your are trying to make the point that consuming dairy products or meat from dairy cows/calves is unethical always and everywhere, and many will argue this is not the case neither form a health perspective, an environmental perspective or an ethical point of view. 